ISSN electrónico: 1885-5210

DOI: https://doi.org/10.14201/rmc202016e311326

\title{
EPIDEMIAS AL ESTILO HOLLYWOOD. UN PEQUEÑO CATÁLOGO
}

\section{Hollywood-style Epidemics. A Short Catalog}

\author{
Manuel SÁNCHEZ-ANGULO \\ Departamento de Producción Vegetal y Microbiología. Campus de Elche. Universidad Miguel Hernández. \\ Elche (España). \\ Correo electrónico: m.sanchez@umh.es
}

Fecha de recepción: 14 de septiembre de 2020

Fecha de aceptación: 16 de septiembre de 2020

Fecha de publicación: 29 de enero de 2021

\section{Resumen}

Las epidemias causadas por microorganismos infecciosos han sido una constante fuente de inspiración para el cine comercial. Muchas películas sobre dicho tópico son bastante famosas y conocidas por el gran público, por lo que pueden ser unas buenas herramientas para explicar diversos conceptos epidemiológicos, inmunológicos y microbiológicos a los estudiantes de carreras biosanitarias. En este trabajo se han recopilado varias de ellas y se han comentado las secuencias más adecuadas para los fines docentes. Aunque una gran parte de las películas de temática epidemiológica suelen recrear situaciones poco plausibles y con escaso rigor científico, no por ello dejan de tener utilidad en su uso como herramientas docentes.

Palabras clave: epidemia; pandemia; virus; zombis; patógenos; biotecnología.

\section{Abstract}

Epidemics caused by infectious microorganisms have been a constant source of inspiration for commercial films. Many films on this topic are quite famous and well known by the general public, so they can be used to explain several epidemiological, immunological and microbiological concepts to university students in health-science degrees. In this work, several films have been selected and their most appropriate sequences for teaching purposes have been commented. 


\section{EPIDEMIAS AL ESTILO HOLLYWOOD. UN PEQUEÑO CATÁLOGO \\ MANUEL SÁNCHEZ-ANGULO}

Although a large part of the films on epidemiological topics usually recreate implausible situations with little scientific rigor, they are still useful in their use as teaching tools.

Keywords: epidemic; pandemic; virus; zombies; pathogens; biotechnology.

\section{INTRODUCCIÓN}

Nadie puede negar que las películas, ya sean vistas en el cine, la televisión o por la web, han forjado una imagen de las enfermedades epidémicas en el imaginario colectivo de la sociedad. Evidentemente, los directores y guionistas se toman unas cuantas licencias artísticas cuando realizan sus obras, pero no hay que olvidar que el cine comercial es un arte que busca entretener. Las representaciones realistas pertenecen al género documental. De todas formas, como microbiólogo, me gusta ver que lo que aparece en la pantalla sea verosímil. Aunque reconozco que, como docente, disfruto de las escenas que contienen un "gazapo científico" que me sirva para introducir y discutir un determinado tema en mis clases ${ }^{1}$. Y el sujeto de las epidemias da para mucho juego.

Según la OMS hay una serie de fases para llegar a una pandemia de gripe ${ }^{2}$, aunque podría valer para cualquier otra enfermedad contagiosa como la actual COVID-19. En la fase 1 los virus están en su reservorio natural y no se han descrito casos de transmisión a humanos. En la fase 2 es cuando hay una zoonosis y el virus ha conseguido saltar a los humanos, pero no hay transmisión entre humanos. En la fase 3 ya hay transmisión entre humanos, pero se trata de grupos pequeños y no hay transmisión comunitaria. Cuando sucede esto último se declara la fase 4 y podemos hablar de un brote epidémico. Todavía puede ser controlada, pero es cada vez más difícil. Si la enfermedad se extiende a varios países de una misma región OMS entonces ya entramos en la fase 5. Y si la epidemia afecta a varios países de diferentes regiones OMS entonces ya se considera una pandemia y se declara la fase 6 . La enfermedad seguirá su curso y llegará a producir un pico de afectados entre la población susceptible. Ese pico será mayor o menor dependiendo de la efectividad de medidas de higiene y salud pública - cuarentenas, aislamientos, medicamentos, vacunas, etc.- que se tomen. Normalmente, una vez pasado ese pico la pandemia remitirá y el número de afectados irá disminuyendo, es lo que se conoce como fase post-pico, aunque pueden darse oleadas epidémicas adicionales por reinfecciones $u$ otras causas. Si la enfermedad remite por completo entonces hablaríamos de la fase post-pandémica.

Pues bien, todas estas fases han sido recreadas en el cine de una u otra manera. Fundamentalmente las fases 3,4 y la fase post-pandemia (Tabla 1). Aunque, en el caso de esa última fase, la recreación suele ser la de un escenario apocalíptico en el que la humanidad ha sido casi totalmente exterminada por la enfermedad o transformada en zombis putrefactos devora-cerebros. Se presenta aquí un catálogo de alguna de las películas en las cuales se pueden encontrar secuencias interesantes, bien por su verosimilitud o bien por todo lo contrario, para ser utilizadas en las clases en las que se discutan temas sobre diversos aspectos científicos como la epidemiología, biotecnología, microbiología o bioética. Se han organizado atendiendo a lo que se ha considerado como el aspecto más destacable de dicha obra.

\section{RIGOR Y ENTRETENIMIENTO}

Comenzaremos este catálogo con cinco películas en las que no se ha sacrificado el rigor científico en aras del tremendismo epidémico, y no por ello han dejado de ser entretenidas e interesantes. 


\section{EPIDEMIAS AL ESTILO HOLLYWOOD. UN PEQUEÑO CATÁLOGO MANUEL SÁNCHEZ-ANGULO}

Tabla 1. Listado de diferentes películas o series en las cuales se representa algún aspecto de la epidemiología de una enfermedad infecciosa. Las películas que aparecen sobre fondo gris son aquellas que no han sido comentadas en este artículo.

\begin{tabular}{|c|c|c|c|c|c|c|}
\hline Título & Director y año & $\begin{array}{l}\text { Origen del } \\
\text { brote }\end{array}$ & $\begin{array}{l}\text { Tipo de } \\
\text { enfermedad }\end{array}$ & $\begin{array}{l}\text { Fases } \\
\text { epidémicas }\end{array}$ & Desenlace & $\begin{array}{l}\text { Terapia } \\
\text { aplicada }\end{array}$ \\
\hline $\begin{array}{l}12 \text { Monos / } \\
12 \text { Monkeys }\end{array}$ & $\begin{array}{l}\text { Terry Gillian } \\
\text { (1995) }\end{array}$ & Arma biológica & Virosis & $\begin{array}{l}\text { Fase } 3 \text { y Post } \\
\text { pandemia }\end{array}$ & $\begin{array}{l}\text { Escenario } \\
\text { post- } \\
\text { apocalíptico }\end{array}$ & \\
\hline 22 ángeles & $\begin{array}{l}\text { Miguel Bardem } \\
(2016)\end{array}$ & $\begin{array}{l}\text { Humano a } \\
\text { humano }\end{array}$ & Viruela & Fase 5 y 6 & Contención & Vacuna \\
\hline $\begin{array}{l}28 \text { días } \\
\text { después / } 28 \\
\text { days later }\end{array}$ & $\begin{array}{l}\text { Danny Boyle } \\
(2002)\end{array}$ & Arma biológica & $\begin{array}{l}\text { Virus de } \\
\text { la rabia } \\
\text { modificado }\end{array}$ & Fase 3 a 5 & $\begin{array}{l}\text { Escenario } \\
\text { post- } \\
\text { apocalíptico }\end{array}$ & \\
\hline $\begin{array}{l}28 \text { semanas } \\
\text { después / } 28 \\
\text { Weeks Later }\end{array}$ & $\begin{array}{l}\text { Juan Carlos } \\
\text { Fresnadillo } \\
\text { (2007) }\end{array}$ & Arma biológica & $\begin{array}{l}\text { Virus de } \\
\text { la rabia } \\
\text { modificado }\end{array}$ & $\begin{array}{l}\text { Fase } 5 \\
\text { Portadores } \\
\text { asintomáticos }\end{array}$ & $\begin{array}{l}\text { Escenario } \\
\text { post- } \\
\text { apocalíptico }\end{array}$ & \\
\hline $\begin{array}{l}93 \text { días / } 93 \\
\text { days }\end{array}$ & $\begin{array}{l}\text { Steve Gukas } \\
(2016)\end{array}$ & $\begin{array}{l}\text { Humano a } \\
\text { humano }\end{array}$ & Virus Ébola & $\begin{array}{l}\text { Fase } 3 \\
\text { Contención }\end{array}$ & $\begin{array}{l}\text { Suero y } \\
\text { cuidados } \\
\text { paliativos }\end{array}$ & \\
\hline 1918 & $\begin{array}{l}\text { Ken Harrison } \\
(1985)\end{array}$ & $\begin{array}{l}\text { Humano a } \\
\text { humano }\end{array}$ & $\begin{array}{l}\text { Gripe H1N1 de } \\
1918\end{array}$ & Fase 5 y 6 & $\begin{array}{l}\text { Extinción de } \\
\text { la pandemia }\end{array}$ & \\
\hline $\begin{array}{l}\text { A ciegas / } \\
\text { Blindness }\end{array}$ & $\begin{array}{l}\text { Fernando } \\
\text { Meirelles (2008) }\end{array}$ & $\begin{array}{l}\text { Humano a } \\
\text { humano }\end{array}$ & $\begin{array}{l}\text { Ceguera por } \\
\text { patógeno } \\
\text { desconocido }\end{array}$ & Fase 3 a 6 & $\begin{array}{l}\text { Distopía post- } \\
\text { pandemia }\end{array}$ & \\
\hline $\begin{array}{l}\text { Apocalipsis / } \\
\text { The Stand }\end{array}$ & $\begin{array}{l}\text { Mick Garris } \\
(1994)\end{array}$ & Arma biológica & $\begin{array}{l}\text { Gripe } \\
\text { hipervirulenta }\end{array}$ & Fase 3 a 6 & $\begin{array}{l}\text { Escenario } \\
\text { post- } \\
\text { apocalíptico }\end{array}$ & \\
\hline Balto & $\begin{array}{l}\text { Simon Wells } \\
(1995)\end{array}$ & $\begin{array}{l}\text { Humano a } \\
\text { humano }\end{array}$ & Difteria & Fase 4 & $\begin{array}{l}\text { Extinción del } \\
\text { brote }\end{array}$ & $\begin{array}{l}\text { Suero } \\
\text { antidiftérico }\end{array}$ \\
\hline $\begin{array}{l}\text { Before } \\
\text { Tomorrow }\end{array}$ & $\begin{array}{l}\text { Marie-Hélène } \\
\text { Cousineau, } \\
\text { Madeline Ivalu } \\
\text { (2008) }\end{array}$ & $\begin{array}{l}\text { Humano a } \\
\text { humano }\end{array}$ & Viruela & Fase 4 & $\begin{array}{l}\text { Extinción del } \\
\text { brote }\end{array}$ & \\
\hline Black Death & $\begin{array}{l}\text { Christopher } \\
\text { Smith (2010) }\end{array}$ & $\begin{array}{l}\text { Humano a } \\
\text { humano }\end{array}$ & Peste bubónica & Fase 4 & $\begin{array}{l}\text { Extinción del } \\
\text { brote }\end{array}$ & \\
\hline Blade & $\begin{array}{l}\text { Stephen } \\
\text { Norrington } \\
\text { (1998) }\end{array}$ & $\begin{array}{l}\text { Humano a } \\
\text { humano }\end{array}$ & $\begin{array}{l}\text { Virus } \\
\text { vampirizante }\end{array}$ & Fases 4 a 6 & Contención & $\begin{array}{l}\text { Virus } \\
\text { recombinante }\end{array}$ \\
\hline Cabin Fever & Eli Roth (2002) & Zoonosis & $\begin{array}{l}\text { Fascitis } \\
\text { necrotizante }\end{array}$ & Fase 2 y 3 & $\begin{array}{l}\text { Extinción del } \\
\text { brote }\end{array}$ & \\
\hline $\begin{array}{l}\text { Contagio / } \\
\text { Contagion }\end{array}$ & $\begin{array}{l}\text { Steven } \\
\text { Soderbergh } \\
(2010)\end{array}$ & Zoonosis & Virus & Fase 1 a 6 & $\begin{array}{l}\text { Escenario } \\
\text { post- } \\
\text { pandemia }\end{array}$ & Vacuna \\
\hline
\end{tabular}

Rev. Med. Cine. 2020; 16 (e), 311-326 Ediciones Universidad de Salamanca / @®® J. Med. Mov., 2020; 16 (e), $311-326$ 
EPIDEMIAS AL ESTILO HOLLYWOOD. UN PEQUEÑO CATÁLOGO MANUEL SÁNCHEZ-ANGULO

\begin{tabular}{|c|c|c|c|c|c|c|}
\hline Título & Director y año & $\begin{array}{l}\text { Origen del } \\
\text { brote }\end{array}$ & $\begin{array}{l}\text { Tipo de } \\
\text { enfermedad }\end{array}$ & $\begin{array}{l}\text { Fases } \\
\text { epidémicas }\end{array}$ & Desenlace & $\begin{array}{l}\text { Terapia } \\
\text { aplicada }\end{array}$ \\
\hline Daybreakers & $\begin{array}{l}\text { The Spierig } \\
\text { Brothers (2009) }\end{array}$ & $\begin{array}{l}\text { Humano a } \\
\text { humano }\end{array}$ & \begin{tabular}{|l} 
Virus \\
vampirizante
\end{tabular} & Post-pandemia & $\begin{array}{l}\text { Extinción del } \\
\text { brote }\end{array}$ & $\begin{array}{l}\text { Breve } \\
\text { exposición } \\
\text { solar y choque } \\
\text { térmico }\end{array}$ \\
\hline $\begin{array}{l}\text { El doctor } \\
\text { Arrowsmith / } \\
\text { Arrowsmith }\end{array}$ & John Ford (1931) & $\begin{array}{l}\text { Humano a } \\
\text { humano }\end{array}$ & Peste bubónica & Fase 4 & $\begin{array}{l}\text { Extinción del } \\
\text { brote }\end{array}$ & $\begin{array}{l}\text { Suero } \\
\text { antibubónico }\end{array}$ \\
\hline $\begin{array}{l}\text { El Corredor } \\
\text { del laberinto } \\
\text { 1, } 2 \text { y } 3 \text { / The } \\
\text { Maze runner } \\
1,2 \text { y } 3\end{array}$ & $\begin{array}{l}\text { Wess Ball 2014, } \\
2015 \text { y } 2018\end{array}$ & Arma biológica & $\begin{array}{l}\text { Virosis } \\
\text { zombificante }\end{array}$ & Post-Pandemia & $\begin{array}{l}\text { Distopia post- } \\
\text { pandemia }\end{array}$ & $\begin{array}{l}\text { Suero } \\
\text { hiperinmune }\end{array}$ \\
\hline $\begin{array}{l}\text { El } \\
\text { experimento } \\
\text { Tuskegee / } \\
\text { Miss Ever's } \\
\text { Boys }\end{array}$ & $\begin{array}{l}\text { Joseph Sargent } \\
\text { (1997) }\end{array}$ & $\begin{array}{l}\text { Humano a } \\
\text { humano }\end{array}$ & Sífilis & Fases 4 & Contención & \\
\hline $\begin{array}{l}\text { El flautista / } \\
\text { The Pied } \\
\text { Piper }\end{array}$ & $\begin{array}{l}\text { Jacques Demy } \\
\text { (1973) }\end{array}$ & Zoonosis & Peste bubónica & Fase 4 & $\begin{array}{l}\text { Extinción del } \\
\text { brote }\end{array}$ & \\
\hline $\begin{array}{l}\text { El húsar en } \\
\text { el tejado / Le } \\
\text { hussard sur } \\
\text { le toit }\end{array}$ & $\begin{array}{l}\text { Jean-Paul } \\
\text { Rappeneau } \\
(1995)\end{array}$ & $\begin{array}{l}\text { Aguas } \\
\text { contaminadas }\end{array}$ & Cólera & Fases 4 y 5 & Contención & $\begin{array}{l}\text { Friegas con } \\
\text { alcohol }\end{array}$ \\
\hline $\begin{array}{l}\text { El Médico / } \\
\text { Der Medicus }\end{array}$ & $\begin{array}{l}\text { Philipp Stölzl } \\
\text { (2013) }\end{array}$ & $\begin{array}{l}\text { Humano a } \\
\text { humano }\end{array}$ & Peste bubónica & Fase 5 & $\begin{array}{l}\text { Extinción del } \\
\text { brote }\end{array}$ & \\
\hline $\begin{array}{l}\text { El origen del } \\
\text { planeta de } \\
\text { los simios / } \\
\text { Rise of the } \\
\text { Planet of the } \\
\text { Apes }\end{array}$ & $\begin{array}{l}\text { Rupert Wyatt } \\
\text { (2011) }\end{array}$ & $\begin{array}{l}\text { Terapia génica } \\
\text { fallida }\end{array}$ & Virosis & Fases 1 a 4 & $\begin{array}{l}\text { Apocalipsis } \\
\text { vírico }\end{array}$ & \\
\hline $\begin{array}{l}\text { El puente de } \\
\text { Cassandra / } \\
\text { The Cassandra } \\
\text { Crossing }\end{array}$ & $\begin{array}{l}\text { George P. } \\
\text { Cosmatos (1976) }\end{array}$ & Arma biológica & $\begin{array}{l}\text { Peste } \\
\text { neumónica }\end{array}$ & Fase 3 & Contención & \\
\hline $\begin{array}{l}\text { El séptimo } \\
\text { sello / Det } \\
\text { sjunde inseglet }\end{array}$ & $\begin{array}{l}\text { Ingmar Bergman } \\
(1957)\end{array}$ & $\begin{array}{l}\text { Humano a } \\
\text { humano }\end{array}$ & Peste bubónica & Fase 5 & $\begin{array}{l}\text { Extinción del } \\
\text { brote }\end{array}$ & \\
\hline $\begin{array}{l}\text { El último } \\
\text { patriota / The } \\
\text { patriot }\end{array}$ & $\begin{array}{l}\text { Dean Semler } \\
(1998)\end{array}$ & Arma biológica & Virosis & Fase 3 & Contención & $\begin{array}{l}\text { Té de hierbas } \\
\text { indígenas }\end{array}$ \\
\hline
\end{tabular}

Rev. Med. Cine. 2020; 16 (e), 311-326 Ediciones Universidad de Salamanca / @®® J. Med. Mov., 2020; 16 (e), $311-326$ 
EPIDEMIAS AL ESTILO HOLLYWOOD. UN PEQUEÑO CATÁLOGO MANUEL SÁNCHEZ-ANGULO

\begin{tabular}{|c|c|c|c|c|c|c|}
\hline Título & Director y año & $\begin{array}{l}\text { Origen del } \\
\text { brote }\end{array}$ & $\begin{array}{l}\text { Tipo de } \\
\text { enfermedad }\end{array}$ & $\begin{array}{l}\text { Fases } \\
\text { epidémicas }\end{array}$ & Desenlace & $\begin{array}{l}\text { Terapia } \\
\text { aplicada }\end{array}$ \\
\hline $\begin{array}{l}\text { El último } \\
\text { valle / The } \\
\text { last valley }\end{array}$ & $\begin{array}{l}\text { James Clavell } \\
(1971)\end{array}$ & $\begin{array}{l}\text { Humano a } \\
\text { humano }\end{array}$ & Peste bubónica & Fase 5 & $\begin{array}{l}\text { Extinción del } \\
\text { brote }\end{array}$ & \\
\hline $\begin{array}{l}\text { El velo } \\
\text { pintado / The } \\
\text { painted veil }\end{array}$ & $\begin{array}{l}\text { John Curran } \\
(2006)\end{array}$ & $\begin{array}{l}\text { Aguas } \\
\text { contaminadas }\end{array}$ & Cólera & Fases 4 y 5 & Contención & $\begin{array}{l}\text { Intervención } \\
\text { de salud } \\
\text { pública }\end{array}$ \\
\hline $\begin{array}{l}\text { En el filo de la } \\
\text { duda / And the } \\
\text { Band Played On }\end{array}$ & $\begin{array}{l}\text { Roger } \\
\text { Spottiswoode } \\
(1993) \\
\end{array}$ & $\begin{array}{l}\text { Humano a } \\
\text { humano }\end{array}$ & VIH & Fase 4 a 6 & $\begin{array}{l}\text { Medidas } \\
\text { preventivas }\end{array}$ & $\begin{array}{l}\text { Terapia } \\
\text { antiretroviral }\end{array}$ \\
\hline $\begin{array}{l}\text { Estación } 3 \\
\text { Ultrasecreto / } \\
\text { The Satan Bug }\end{array}$ & $\begin{array}{l}\text { John Sturges } \\
(1965)\end{array}$ & Arma biológica & $\begin{array}{l}\text { Virus } \\
\text { sarampión } \\
\text { modificado }\end{array}$ & Fase 3 & Contención & \\
\hline $\begin{array}{l}\text { Estallido / } \\
\text { Outbreak }\end{array}$ & $\begin{array}{l}\text { Wolfgang } \\
\text { Petersen (1995) }\end{array}$ & Zoonosis & $\begin{array}{l}\text { Fiebre } \\
\text { hemorrágica }\end{array}$ & Fases 2 a 4 & Contención & $\begin{array}{l}\text { Suero } \\
\text { hiperinmune }\end{array}$ \\
\hline $\begin{array}{l}\text { Fast \& Furious: } \\
\text { Hobbs \& Shaw }\end{array}$ & $\begin{array}{l}\text { David Leitch } \\
\text { (2019) }\end{array}$ & Arma biológica & Virosis & Fase 3 & Contención & $\begin{array}{l}\text { Mecanismo } \\
\text { nano- } \\
\text { tecnológico }\end{array}$ \\
\hline $\begin{array}{l}\text { Guerra } \\
\text { Mundial Z / } \\
\text { World War Z }\end{array}$ & $\begin{array}{l}\text { Marc Forster } \\
(2013)\end{array}$ & $\begin{array}{l}\text { ¿Arma } \\
\text { biológica? }\end{array}$ & $\begin{array}{l}\text { Virosis } \\
\text { zombificante }\end{array}$ & Fases 4 a 6 & $\begin{array}{l}\text { Post- } \\
\text { Apocalipsis y } \\
\text { recuperación }\end{array}$ & Vacuna \\
\hline In the flesh & $\begin{array}{l}\text { Dominic Mitchell } \\
(2013)\end{array}$ & $\begin{array}{l}\text { Humano a } \\
\text { humano }\end{array}$ & \begin{tabular}{|l} 
Virosis \\
zombificante
\end{tabular} & $\begin{array}{l}\text { Fase } \\
\text { post-pandemia }\end{array}$ & Contención & $\begin{array}{l}\text { Fármaco } \\
\text { antiviral }\end{array}$ \\
\hline Infección & $\begin{array}{l}\text { Flavio Pedota } \\
(2019)\end{array}$ & $\begin{array}{l}\text { Humano a } \\
\text { humano }\end{array}$ & $\begin{array}{l}\text { Virus de la } \\
\text { rabia mutado }\end{array}$ & Fase 3 a 5 & Contención & Vacuna \\
\hline $\begin{array}{l}\text { Infectados / } \\
\text { Carriers }\end{array}$ & $\begin{array}{l}\text { David Pastor, Alex } \\
\text { Pastor (2009) }\end{array}$ & $\begin{array}{l}\text { Humano a } \\
\text { humano }\end{array}$ & Virosis & $\begin{array}{l}\text { Fase } \\
\text { post-pandemia }\end{array}$ & \begin{tabular}{|l} 
Post- \\
apocalipsis
\end{tabular} & \\
\hline Inferno & $\begin{array}{l}\text { Ron Howard } \\
(2016)\end{array}$ & Arma biológica & Virosis & Fase 2 & Contención & \\
\hline $\begin{array}{l}\text { Invasión / } \\
\text { The Invasion }\end{array}$ & \begin{tabular}{|l} 
Oliver \\
Hirschbiegel, \\
James McTeigue \\
(2007) \\
\end{tabular} & $\begin{array}{l}\text { Arma biológica } \\
\text { Extraterrestre }\end{array}$ & $\begin{array}{l}\text { Virosis } \\
\text { neuropática }\end{array}$ & Fase 3 a 6 & Contención & Vacuna \\
\hline $\begin{array}{l}\text { La amenaza de } \\
\text { Andrómeda / } \\
\text { The } \\
\text { Andromeda } \\
\text { Strain }\end{array}$ & $\begin{array}{l}\text { Robert Wise } \\
(1971)\end{array}$ & Extraterrestre & $\begin{array}{l}\text { Infección } \\
\text { sistémica }\end{array}$ & Fase 4 & $\begin{array}{l}\text { Contención } \\
\text { Evolución del } \\
\text { patógeno }\end{array}$ & \\
\hline $\begin{array}{l}\text { La gripe / } \\
\text { Gamgi }\end{array}$ & $\begin{array}{l}\text { Sung-su Kim } \\
(2013)\end{array}$ & $\begin{array}{l}\text { Humano a } \\
\text { humano }\end{array}$ & $\begin{array}{l}\text { Virus gripe } \\
\text { H1N1 }\end{array}$ & Fase 4 y 5 & Contención & \\
\hline $\begin{array}{l}\text { La máscara } \\
\text { de la Muerte } \\
\text { Roja / The } \\
\text { Mask of the } \\
\text { Red Death }\end{array}$ & $\begin{array}{l}\text { Roger Corman } \\
(1964)\end{array}$ & $\begin{array}{l}\text { Humano a } \\
\text { humano }\end{array}$ & $\begin{array}{l}\text { Peste } \\
\text { hipervirulenta }\end{array}$ & Fase 4 y 5 & $\begin{array}{l}\text { Extinción del } \\
\text { brote }\end{array}$ & \\
\hline
\end{tabular}

Rev. Med. Cine. 2020; 16 (e), 311-326 Ediciones Universidad de Salamanca / @®® J. Med. Mov., 2020; 16 (e), $311-326$ [ 315 ] 
EPIDEMIAS AL ESTILO HOLLYWOOD. UN PEQUEÑO CATÁLOGO

MANUEL SÁNCHEZ-ANGULO

\begin{tabular}{|c|c|c|c|c|c|c|}
\hline Título & Director y año & $\begin{array}{l}\text { Origen del } \\
\text { brote }\end{array}$ & $\begin{array}{l}\text { Tipo de } \\
\text { enfermedad }\end{array}$ & $\begin{array}{l}\text { Fases } \\
\text { epidémicas }\end{array}$ & Desenlace & $\begin{array}{l}\text { Terapia } \\
\text { aplicada }\end{array}$ \\
\hline La peste & $\begin{array}{l}\text { Luis Puenzo } \\
\text { (1992) }\end{array}$ & $\begin{array}{l}\text { Humano a } \\
\text { humano }\end{array}$ & Peste bubónica & Fase 4 y 5 & $\begin{array}{l}\text { Extinción del } \\
\text { brote }\end{array}$ & \\
\hline La peste & $\begin{array}{l}\text { Rafael Cobos, } \\
\text { Alberto } \\
\text { Rodríguez (2018) }\end{array}$ & $\begin{array}{l}\text { Humano a } \\
\text { humano }\end{array}$ & Peste bubónica & Fase 4 y 5 & $\begin{array}{l}\text { Extinción del } \\
\text { brote }\end{array}$ & \\
\hline $\begin{array}{l}\text { La puta del } \\
\text { rey / La } \\
\text { putain du roi }\end{array}$ & Axel Corti (1990) & $\begin{array}{l}\text { Humano a } \\
\text { humano }\end{array}$ & Viruela & Fase 4 & Contención & \\
\hline $\begin{array}{l}\text { Los señores } \\
\text { del acero / } \\
\text { Flesh and } \\
\text { blood }\end{array}$ & $\begin{array}{l}\text { Paul Verhoeven } \\
\text { (1985) }\end{array}$ & Zoonosis & Peste bubónica & Fase 4 & $\begin{array}{l}\text { Extinción del } \\
\text { brote }\end{array}$ & \\
\hline $\begin{array}{l}\text { Los últimos } \\
\text { días del } \\
\text { Edén / } \\
\text { Medicine } \\
\text { Man }\end{array}$ & $\begin{array}{l}\text { John McTiernan } \\
\text { (1992) }\end{array}$ & $\begin{array}{l}\text { Humano a } \\
\text { humano }\end{array}$ & Gripe & Fase 4 & $\begin{array}{l}\text { Extinción del } \\
\text { brote }\end{array}$ & \\
\hline Maggie & $\begin{array}{l}\text { Henry Hobson } \\
\text { (2015) }\end{array}$ & $\begin{array}{l}\text { Humano a } \\
\text { humano }\end{array}$ & $\begin{array}{l}\text { Virosis } \\
\text { zombificante }\end{array}$ & Fase 6 & $\begin{array}{l}\text { La pandemia } \\
\text { continua }\end{array}$ & \\
\hline $\begin{array}{l}\text { Melanie: The } \\
\text { Girl with All } \\
\text { the Gifts }\end{array}$ & $\begin{array}{l}\text { Colm McCarthy } \\
(2016)\end{array}$ & Zoonosis & $\begin{array}{l}\text { Micosis } \\
\text { zombificante }\end{array}$ & Post-Pandemia & $\begin{array}{l}\text { Post- } \\
\text { Apocalipsis }\end{array}$ & \\
\hline $\begin{array}{l}\text { Misión } \\
\text { Imposible 2/ } \\
\text { Mission: } \\
\text { Impossible II }\end{array}$ & John Woo (2000) & Arma biológica & $\begin{array}{l}\text { Virus gripe } \\
\text { hipervirulento }\end{array}$ & Fase 3 & Contención & Antiviral \\
\hline $\begin{array}{l}\text { Pánico en las } \\
\text { calles / Pánic } \\
\text { in the Streets }\end{array}$ & Elia Kazan (1950) & $\begin{array}{l}\text { Humano a } \\
\text { humano }\end{array}$ & $\begin{array}{l}\text { Peste } \\
\text { neumónica }\end{array}$ & Fase 3 & Contención & $\begin{array}{l}\text { Vacuna Suero } \\
\text { Antibiótico }\end{array}$ \\
\hline REC & $\begin{array}{l}\text { Jaume Balagueró, } \\
\text { Paco Plaza (2007) }\end{array}$ & Zoonosis & $\begin{array}{l}\text { Virosis } \\
\text { zombificante } \\
\text { Parasitosis }\end{array}$ & Fase 4 & Contención & \\
\hline $\begin{array}{l}\text { Retornados / } \\
\text { The Returned }\end{array}$ & $\begin{array}{l}\text { Manuel Carballo } \\
\text { (2013) }\end{array}$ & $\begin{array}{l}\text { Humano a } \\
\text { humano }\end{array}$ & $\begin{array}{l}\text { Virosis } \\
\text { zombificante }\end{array}$ & $\begin{array}{l}\text { Fase } \\
\text { post-pandemia }\end{array}$ & Contención & $\begin{array}{l}\text { Terapia por } \\
\text { proteína } \\
\text { recombinante }\end{array}$ \\
\hline $\begin{array}{l}\text { Resident Evil: } \\
\text { El capítulo } \\
\text { final / } \\
\text { Resident Evil: } \\
\text { The Final } \\
\text { Chapter }\end{array}$ & $\begin{array}{l}\text { Paul W.S. } \\
\text { Anderson (2016) }\end{array}$ & $\begin{array}{l}\text { Terapia génica } \\
\text { fallida }\end{array}$ & $\begin{array}{l}\text { Virosis } \\
\text { zombificante }\end{array}$ & $\begin{array}{l}\text { Fases } 3 \text { a } 6 \text { y } \\
\text { post-pandemia }\end{array}$ & $\begin{array}{l}\text { Post- } \\
\text { Apocalipsis }\end{array}$ & Virofago \\
\hline
\end{tabular}

Rev. Med. Cine. 2020; 16 (e), 311-326 Ediciones Universidad de Salamanca / @®® J. Med. Mov., 2020; 16 (e), $311-326$ 
EPIDEMIAS AL ESTILO HOLLYWOOD. UN PEQUEÑO CATÁLOGO

MANUEL SÁNCHEZ-ANGULO

\begin{tabular}{|c|c|c|c|c|c|c|}
\hline Título & Director y año & $\begin{array}{l}\text { Origen del } \\
\text { brote }\end{array}$ & $\begin{array}{l}\text { Tipo de } \\
\text { enfermedad }\end{array}$ & $\begin{array}{l}\text { Fases } \\
\text { epidémicas }\end{array}$ & Desenlace & $\begin{array}{l}\text { Terapia } \\
\text { aplicada }\end{array}$ \\
\hline $\begin{array}{l}\text { Señal de } \\
\text { alarma / } \\
\text { Warning } \\
\text { Sign }\end{array}$ & $\begin{array}{l}\text { Hal Barwood } \\
(1985)\end{array}$ & Arma biológica & $\begin{array}{l}\text { Infección } \\
\text { bacteriana } \\
\text { sistémica }\end{array}$ & Fase 3 & Contención & \\
\hline $\begin{array}{l}\text { Sin control / } \\
\text { Derailed }\end{array}$ & $\begin{array}{l}\text { Bob Misiorowski } \\
\text { (2002) }\end{array}$ & Arma biológica & $\begin{array}{l}\text { Viruela } \\
\text { modificada }\end{array}$ & Fase 3 & Contención & \\
\hline Soy Leyenda & $\begin{array}{l}\text { Mario Gómez } \\
\text { Martín (1967) }\end{array}$ & Arma biológica & $\begin{array}{l}\text { Bacteriemia } \\
\text { vampirizante }\end{array}$ & $\begin{array}{l}\text { Fases } 4 \text { y } \\
\text { post-pandemia, }\end{array}$ & $\begin{array}{l}\text { Distopia post- } \\
\text { apocalíptica }\end{array}$ & \\
\hline $\begin{array}{l}\text { Soy Leyenda / } \\
\text { I am Legend }\end{array}$ & $\begin{array}{l}\text { Francis Lawrence } \\
(2007)\end{array}$ & $\begin{array}{l}\text { Terapia génica } \\
\text { fallida }\end{array}$ & $\begin{array}{l}\text { Virosis } \\
\text { vampirizante }\end{array}$ & $\begin{array}{l}\text { Fases 2, } 5 \text { y } \\
\text { post-pandemia, }\end{array}$ & $\begin{array}{l}\text { Post- } \\
\text { Apocalipsis y } \\
\text { recuperación }\end{array}$ & $\begin{array}{l}\text { Suero } \\
\text { hiperinmune } \\
\text { Vacuna }\end{array}$ \\
\hline The Crazies & $\begin{array}{l}\text { George A. } \\
\text { Romero (1973) }\end{array}$ & Arma biológica & $\begin{array}{l}\text { Virus de } \\
\text { la rabia } \\
\text { modificado }\end{array}$ & Fase 3 y 4 & $\begin{array}{l}\text { Diseminación } \\
\text { del virus }\end{array}$ & \\
\hline $\begin{array}{l}\text { The Walking } \\
\text { Dead }\end{array}$ & $\begin{array}{l}\text { Frank Darabont, } \\
\text { Angela Kang } \\
\text { (2010) }\end{array}$ & $\begin{array}{l}\text { Humano a } \\
\text { humano }\end{array}$ & $\begin{array}{l}\text { Activación } \\
\text { virus } \\
\text { endógeno }\end{array}$ & $\begin{array}{l}\text { Fases } 3 \text { a } 6 \text { y } \\
\text { post-pandemia }\end{array}$ & $\begin{array}{l}\text { Post- } \\
\text { Apocalipsis }\end{array}$ & \\
\hline $\begin{array}{l}\text { Train to } \\
\text { Busan / } \\
\text { Busanhaeng }\end{array}$ & $\begin{array}{l}\text { Sang-ho Yeon } \\
(2016)\end{array}$ & $\begin{array}{l}\text { Humano a } \\
\text { humano }\end{array}$ & $\begin{array}{l}\text { Virus } \\
\text { zombificante }\end{array}$ & Fases 4 a 5 & Contención & \\
\hline $\begin{array}{l}\text { Un asunto } \\
\text { real / En } \\
\text { kongelig } \\
\text { affære }\end{array}$ & $\begin{array}{l}\text { Nikolaj Arcel } \\
(2012)\end{array}$ & $\begin{array}{l}\text { Humano a } \\
\text { humano }\end{array}$ & Viruela & Fase 5 & Contención & Variolizacion \\
\hline $\begin{array}{l}\text { V de } \\
\text { Vendetta / } \\
\text { V for } \\
\text { Vendetta }\end{array}$ & $\begin{array}{l}\text { James McTeigue } \\
(2005)\end{array}$ & Arma biológica & Virosis & Post-pandemia & $\begin{array}{l}\text { Distopia post- } \\
\text { pandemia }\end{array}$ & \\
\hline Variola Vera & $\begin{array}{l}\text { Goran Markovic } \\
(1982)\end{array}$ & $\begin{array}{l}\text { Humano a } \\
\text { humano }\end{array}$ & Viruela & Fases 4 a 5 & Contención & \\
\hline Virus & $\begin{array}{l}\text { Aashiq Abu } \\
\text { (2019) } \\
\end{array}$ & $\begin{array}{l}\text { Humano a } \\
\text { humano }\end{array}$ & Virus Nipah & Fases 3 a 4 & Contención & \\
\hline Yeon-ga-si & $\begin{array}{l}\text { Park Jeong-woo } \\
(2012)\end{array}$ & $\begin{array}{l}\text { Zoonosis } \\
\text { artificial }\end{array}$ & Parasitosis & Fases 2 a 4 & Contención & Antiparasitario \\
\hline
\end{tabular}

Pánico en las calles / Panic in the Streets (Elia Kazan, 1950). Puede afirmarse que Kazan inventó el género del thriller médico con esta película. Un inmigrante enfermo de peste neumónica llega a la ciudad de Nueva Orleans. Las autoridades sanitarias intentarán controlar el brote, pero procurarán hacerlo de la manera más discreta posible para evitar el pánico y que la gente abandone la ciudad, lo que supondría la diseminación de la plaga por todo el país. Richard Widmark da 


\section{EPIDEMIAS AL ESTILO HOLLYWOOD. UN PEQUEÑO CATÁLOGO}

MANUEL SÁNCHEZ-ANGULO

vida a Clint Reed (¿será un guiño a la figura de Walter Reed?) un oficial de sanidad pública que será acompañado por un "duro" comisario, interpretado por Paul Douglas, en su labor de intentar trazar los contactos del enfermo, aislarlos y someterlos a una profilaxis usando una vacuna, suero y el antibiótico estreptomicina. Hay que destacar también el papel de Jack Palance en el papel de hampón de los bajos fondos de Nueva Orleans ${ }^{3}$.

La amenaza de Andrómeda / The Andromeda Strain (Robert Wise, 1971). Un tecno-thriller en el cual un grupo de científicos debe de intentar contener la expansión de un patógeno extraterrestre. Robert Wise adaptó magistralmente la novela de Michael Crichton, y aunque han pasado más de 50 años desde su estreno, podemos encontrar en sus fotogramas temas tan de actualidad como los laboratorios de alta seguridad biológica, las medidas de aislamiento y protección personal, o el proceso de toma de decisiones ante una grave situación inesperada. En la película se muestra el funcionamiento correcto de diverso equipamiento científico, como el microscopio electrónico de transmisión, el ultramicrotomo, o los sistemas de cultivo microbiológico ${ }^{4}$.

En el filo de la duda / And the band played on (Roger Spottiswoode, 2003). Una película que pasó desapercibida en su momento pero que nos relata en un tono casi documental los primeros pasos de la lucha epidemiológica contra el SIDA y de toda la polémica científica que rodeó al descubrimiento del VIH. La película finaliza con el mensaje de que la importancia que tiene la actuación temprana para intentar paliar los efectos de una pandemia.

El velo pintado / The painted veil (John Curran, 2006). Los brotes de cólera han aparecido en otras películas famosas como por ejemplo en Muerte en Venecia / Morte a Venezia (Luccino Visconti, 1971) o en El húsar en el tejado / Le hussard sur le toit (Jean-Paul Rappeneau, 1985). Pero en esta película protagonizada por Edward Norton y Naomi Watts hay varias secuencias a destacar por su interés bacteriológico. Quizás las más impactante es la dedicada a la visita al hospital donde se muestra de manera muy gráfica los síntomas de tan terrible enfermedad. Otro aspecto a destacar es cómo se refleja el choque entre tradición y modernidad representado con los problemas de salud pública derivados por las tradiciones funerarias. Algo que hemos visto repetido por ejemplo con la epidemia del virus Ébola del 2014.

Contagio / Contagion (Steven Soderbergh, 2011) es la única película en la que se muestran de una manera realista y con bastante rigor científico, todas las fases epidemiológicas descritas anteriormente. A través de una serie de historias paralelas cuyo nexo común es la pandemia de un virus, Soderbergh nos lleva desde los murciélagos de las selvas asiáticas hasta los esfuerzos de la OMS para contener la enfermedad. En mi opinión, lo mejor de esta película es que el tiempo la ha puesto en su lugar, pues anticipó una serie de situaciones que hemos vivido o que estamos viviendo en la actualidad con la pandemia de COVID-19: las mascarillas, los confinamientos, los aeropuertos desiertos, los charlatanes que tratan de aprovecharse, la carrera científica por desarrollar una vacuna y las controvertidas decisiones de los políticos que afectarán a la vida de millones de personas. Al contrario que en otras producciones aquí la acción no ocurre en horas o en días, sino en meses y años. Una vez se ha superado el pico pandémico y que se ha conseguido desarrollar una vacuna vemos que la sociedad intenta volver a la normalidad poco a poco. Una cuestión bioética es que la vacuna se está administrando a la población mediante unas pautas predeterminadas por cada gobierno: primero a segmentos "esenciales" como es el personal médico y luego a la población mediante un sorteo basado en la fecha de nacimiento. También se muestra cómo en esa nueva normalidad, las personas portan un "pasaporte inmunológico" en el que se informa si están vacunados o si son resistentes naturales a la 
enfermedad. Por ahora, es una de las pocas cosas que aún no se ha cumplido de dicha película ${ }^{5}$.

\section{ZOONOSIS}

El origen de muchas de las plagas que han asolado a la humanidad está en los animales con los que entramos en contacto al invadir sus hábitats y esto se ha representado en varias películas con mayor o menor fortuna.

Estallido / Outbreak (Wolfgang Petersen, 1995). Protagonizada por el mono capuchino más famoso del cine. Dicho primate no porta una, sino dos cepas distintas de un filovirus letal: una se transmite por fluidos y contacto directo, la otra por vía aérea. En la película el virus Motaba funciona como un Ébola acelerado, ya que los afectados desarrollan los síntomas hemorrágicos en cuestión de horas. Hay varias secuencias destacables como es la dispersión aérea del virus dentro de una sala de cine llena de público. $Y$ probablemente es una de las primeras veces que vemos el recurso visual de un mapa en el que se modeliza la epidemia y que acaba tornándose completamente rojo. También hay un "homenaje" a la película Pánico en las calles en la secuencia de abordaje al barco que ha llevado el mono capuchino a Norteamérica. Hay que reconocer que Estallido es muy entretenida y funciona bien como película de catástrofes, aunque la cinta está plagada de errores científicos, como por ejemplo la secuencia en la que Dustin Hoffman le ordena a Cuba Gooding Jr. que sintetice litros de suero en cuestión de horas, a partir de un mono capuchino de dos kilos de peso iy lo consigue! Sería interesante calcular el título de anticuerpos de la sangre del mono ${ }^{6}$.

Cabin fever (Eli Roth, 2002). Típica película gore con un grupo de jóvenes aislados en medio de una cabaña del bosque. Un perro afectado por fascitis necrotizante (no indican que pueda ser por Streptococcus pyogenes) es el origen de un brote que va a afectar a los protagonistas. El patógeno se transmite por contacto con los fluidos corporales de un infectado, por fómites o por el agua. Lo más destacable es que muestra cómo las personas pueden desarrollar un comportamiento insolidario por miedo a contagiarse de una enfermedad mortal e incurable.

Yeon-ga-si (Jeong-woo, Park 2012). Esta película coreana no ha sido estrenada en España, pero puede encontrarse en algunas plataformas con el título de Deranged. En ese caso el patógeno no es un virus, sino gusanos nematomorfos parásitos conocidos como "pelo de caballo". Las larvas de estos parásitos crecen en el interior de los insectos y toman el control del hospedador forzándoles a buscar alguna charca donde arrojarse. Una vez en el agua, el gusano adulto sale del interior del insecto como si fuera una cría de Alien y continúa su ciclo. Se han dado casos esporádicos de infección en vertebrados, incluido humanos. En esta película, los científicos de una compañía biotecnológica tienen un proyecto de investigación financiado por el gobierno en el que modifican los gusanos para desarrollar una cura contra el Alzheimer. El gusano es capaz de actuar sobre el cerebro evitando la enfermedad y a su vez es controlado mediante un antiparasitario para evitar que el hospedador perezca. Pero un día el gobierno les retira los fondos, así que, en lugar de lamentarse, rellenar un curriculum y pedir otro proyecto, lo que hacen es contaminar el suministro de aguas de una ciudad. De esa manera se desatará un brote de gente que no para de comer y que luego se arroja al río para expulsar a los gusanos. Para pararlo el gobierno parece no tener otra opción que comprar a precio de oro el antiparasitario que ellos han desarrollado. Moraleja, no dejes sin fondos a tus científicos porque pueden transformarse en científicos locos.

Melanie, the girl with all the gifts (Colm McCarthy, 2016). El patógeno es un mutante del hongo Ophiocordyceps unilateralis que, en lugar de infectar hormigas, ahora es capaz de infectar humanos y convertirlos en zombis para 


\section{EPIDEMIAS AL ESTILO HOLLYWOOD. UN PEQUEÑO CATÁLOGO \\ MANUEL SÁNCHEZ-ANGULO}

así completar su ciclo biológico. Aunque hay una notable excepción, en el caso de los niños que estaban en gestación cuando la madre fue infectada el hongo consigue desarrollar una simbiosis. Puede decirse que la trama está inspirada en el videojuego The Last of Us y en la famosa novela de Richard Matheson Soy leyenda. Puede ser útil para discutir sobre cuestiones bioéticas sobre lo que significa ser un ser humano o para utilizarlo en una clase de micología. La película también contiene un guiño a las mujeres científicas, pues uno de los laboratorios móviles lleva el nombre de Rosalind Franklin.

[•REC] (Jaume Balagueró y Paco Plaza, 2007). Al lector le puede sorprender la inclusión de esta película en este apartado, pero es que en REC 4: Apocalipsis (Jaume Balagueró, 2014), se nos explica que el virus zombificante proviene de un parásito parecido a un anélido. Lo cierto es que el ciclo biológico del parásito es un simple Macguffin para justificar el absurdo argumento de esa cuarta parte. Volviendo a la primera película de la saga, está rodada a modo de falso documental y fue un gran éxito de crítica y público, ya que consigue mezclar el género de zombis con una trama que a mí me recordó a la comunidad de vecinos de la serie Aquí no hay quien viva (2003). Un bloque de viviendas es confinado debido a la aparición de un brote de una enfermedad similar a la rabia, pero mucho más contagiosa. Hay que recordar que los casos de rabia serían un ejemplo de Fase 2 , tal y como puede verse en Cujo (Lewis Teague, 1982). Pero en este caso, lo que tenemos es una enfermedad que es capaz de transmitirse entre humanos (Fase 3) y que se manifiesta más o menos rápido dependiendo de la fisiología del hospedador. En algunos la transformación es cuestión de minutos, pero en otros es cuestión de horas.

\section{CUANDO LA TERAPIA GÉNICA FUNCIONA MAL}

En la actualidad la terapia génica utilizando vectores víricos parece una de las mejores alternativas en el tratamiento de diversas enfermedades, desde el cáncer hasta enfermedades genéticas. Sin embargo, estos avances biotecnológicos no han sido representados precisamente de esa manera tan positiva. Podríamos decir que el miedo a crear un Frankenstein biotecnológico todavía perdura en el cine.

Soy Leyenda / I am Legend (Francis Lawrence, 2007). La novela de Richard Matheson ha sido llevada al celuloide en numerosas ocasiones. Incluso hay una versión española en formato cortometraje (Soy Leyenda, Mario Gómez Martín, 1967) que está considerada como la adaptación más fiel al libro original. En esta última versión, la causa de la plaga que acaba con la humanidad es un virus oncolítico que es capaz de curar el cáncer, pero que transforma a los humanos en una especie de vampiros-zombificados ${ }^{7}$. Will Smith interpreta a un virólogo que tiene una resistencia innata al virus y que trata de desarrollar una cura, así que en la película veremos que tiene montado todo un laboratorio de biología molecular con animalario incluido en su casa-fortaleza.

El origen del planeta de los simios / Rise of the Planet of the Apes (Rupert Wyatt, 2011). James Franco da vida a un científico de una compañía biotecnológica en la que se está desarrollando una terapia contra el Alzheimer utilizando un retrovirus para activar la neurogénesis en los pacientes tratados ${ }^{8}$. Sin embargo, la terapia falla porque los pacientes desarrollan inmunidad frente al retrovirus. Así que, para superar al sistema inmunitario, lo que hacen es utilizar un virus más virulento y que además se transmite por vía aérea. Inicialmente parece tener éxito porque los humanos se curan del Alzheimer, pero a las 48 horas se mueren de una hemorragia cerebral. Mientras tanto, el virus vuelve inteligentes a los simios. Lo más destacable desde el punto de vista epidemiológico es la secuencia final antes de los títulos de crédito. El piloto de una compañía comercial es infectado y vemos como llega 
al aeropuerto. La imagen pasa a mostrarnos un mapamundi con la ciudad de San Francisco que se va volviendo roja por la infección y de ella sale una línea que cruza el continente para alcanzar Nueva York. A partir de ahí, vemos como la enfermedad va diseminándose por todo el planeta. Una secuencia similar, pero esta vez acompañada de imágenes sobre disturbios y situaciones de confinamiento, se utiliza en el comienzo de la siguiente película de la saga, El amanecer del planeta de los simios / Dawn of the Planet of the Apes (Matt Reeves, 2014).

Resident Evil: The Final Chapter (Paul W.S. Anderson, 2016). En el año 2002 se estrenó la primera película de esta famosa saga en la que un virus zombificante acaba prácticamente con toda la humanidad convirtiéndola en zombis putrefactos o en mutantes monstruosos. Es en la sexta entrega cuando se nos explica el origen del virus-T que ha causado todo ese caos. Resulta que fue desarrollado como terapia génica para curar la progeria en niños. El virus-T revertía la enfermedad, lo malo es que tenía el efecto secundario de convertir a los niños en zombis y estos luego se comían a sus padres y amiguitos. También es en esa sexta entrega donde describen la cura a base de un virófago, un virus del virus-T que se transmite por vía aérea.

\section{EPIDEMIAS Y CINE HISTÓRICO}

Las enfermedades infecciosas llevan con nosotros desde antes que fuéramos humanos. Así que no es extraño que aparezcan representadas en varias películas de temática histórica.

1918 (Ken Harrison, 1985) Si no estoy equivocado creo que esta es la única película en la aparece reflejada una de las peores pandemias sufridas por la humanidad. La pandemia de gripe de 1918, mal llamada gripe española, se estima que acabó con la vida de al menos 50 millones de personas y afectó a diez veces más. Es una película para televisión que no es fácil de encontrar. La historia transcurre en una pequeña localidad de
Texas. Inicialmente la vida transcurre de manera apacible y la gripe parece una afección invernal más. Pero poco a poco los afectados aumentan y muchos de ellos son jóvenes, con lo que los parques y los cines van quedando desiertos.

La Peste (Alberto Rodríguez Librero, 2018). Para los cinéfilos la película más famosa sobre la llamada "muerte negra" es la obra maestra El séptimo sello / Det sjunde inseglet (Ingmar Bergman, 1957), pero esta serie de televisión es algo más reciente $y$, probablemente, sea más conocida entre el público más joven. Aunque está llena de tópicos de la leyenda negra no por eso deja de ser interesante verla. Sevilla sufrió varios brotes de peste a lo largo de su historia y aunque en la serie se dice que el año es 1597 pero la situación epidémica que describen es la del brote de 1649 . Otro anacronismo lo tenemos en la secuencia en la que se muestra el tenebroso interior del hospital. De manera muy breve, pero tétrica, vemos un "médico de la peste" caminando entre los pacientes. Ese tipo de antiguo traje de bioseguridad fue inventado por el francés Charles de Lorme en 1620. Aunque quizás el gazapo más destacable afecta al personaje del médico Nicolás Monardes (interpretado por Tomás del Estal). Monardes vivió entre 1493 y 1588. Fue uno de los pioneros de la botánica, conocido en toda Europa por su obra "Historia medicinal de las cosas que se traen de nuestras Indias Occidentales", escrita en 1560 con todos los parabienes de la corona y traducida a diversos idiomas como el inglés y el francés. En esa obra habla del uso de las plantas como la piña, el tabaco, el maíz o los cacahuetes. Así que lo de que "le quemarían por brujo" queda muy bien para la trama, pero es totalmente ficticio.

La puta del rey / La putain du roi (Axel Corti, 1990), Un asunto real / En kongelig affære (Nikolaj Arcel, 2012) y la serie 22 ángeles (Miguel Bardem, 2016) tienen el nexo común de que describe el azote que suponían las epidemias de 


\section{EPIDEMIAS AL ESTILO HOLLYWOOD. UN PEQUEÑO CATÁLOGO \\ MANUEL SÁNCHEZ-ANGULO}

viruela en la Europa de finales del XVIII ${ }^{9}$. Aunque de diferentes calidades cinematográficas, cada una de ellas tiene un aspecto que merece la pena destacar. En la primera, Axel Corti consigue transmitir el padecimiento de los afectados de una manera bastante realista mediante una secuencia en la que vemos como el rey Víctor Amadeo II (Timothy Dalton) debe de atar a la cama a su amante enferma (Valeria Golino) para evitar que se rasque las pústulas y así poder ser cuidada. En la interesante película danesa se describe como el médico Johann Frederich, interpretado por Mads Mikkelsen, aplica la variolización al hijo del rey y luego establece dicha práctica como obligatoria en el reino escandinavo (en la versión española se habla de la "vacunación"). Finalmente, la serie española está dedicada a describir la Real Expedición Filantrópica de la Vacuna para llevar la vacuna a las tierras españolas allende el Atlántico. Esta historia tan interesante sobre los médicos Francisco Javier de Balmis y José Salvany Lleopart, la enfermera Isabel Zendal Gómez y los 22 huérfanos, se ve lastrada por una producción algo pobre y un argumento lleno de tópicos como un triángulo amoroso entre los protagonistas y conspiraciones clericales para evitar la vacunación.

\section{ARMAS BIOLÓGICAS}

Podría decirse que hay una subclase de películas cuya trama se resume de la siguiente manera: cómo contener una infección provocada por el uso de un arma biológica. En estas películas abundan los soldados con trajes de protección biológica, las conspiraciones gubernamentales o empresariales, y por supuesto, mucha acción. Lo que no suele prodigarse es la rigurosidad científica.

Estación 3 ultrasecreto / The Satan Bug (John Sturges, 1965). Probablemente la primera película en la que se habla de laboratorios militares de armas biológicas. En este caso un terrorista ha conseguido robar unos viales de toxina botulínica y de un virus del sarampión denominado "Satan" que ha sido modificado para que infecte y mate a cualquier vertebrado $y$ que sea capaz de multiplicarse sin necesidad de hospedador, por lo que si es liberado no podría ser contenido de ninguna manera.

The Crazies (George A. Romero, 1973). George A. Romero no solo es el creador del género de zombis tal y como lo conocemos, también fue el primero en realizar una película en la cual los militares desarrollan un virus de la rabia modificado que enloquecen a las personas para que se ataquen las unas a las otras. Lo más destacable de la película es que muestra como la incompetencia en los diferentes niveles, militar, político y científico, puede provocar que un brote epidémico se extienda sin control. En el año 2010 se realizó un remake dirigido por Breck Eisner en el que el virus además provocaba el síndrome de Stevens-Johnson, lo que le daba a los afectados un aspecto más parecido al de un zombi.

El puente de Cassandra / The Cassandra Crossing (George Pan Cosmatos, 1976). Una típica película de catástrofes de los años 70 con un elenco de grandes actores como Sofía Loren, Ava Gadner, Burt Lancaster o Richard Harris, en horas bajas. La trama es bastante increíble, y consiste en que unos terroristas asaltan un laboratorio secreto estadounidense que está situado en plena sede de la OMS en Ginebra y se llevan una cepa de peste neumónica hipervirulenta a un tren que realiza el recorrido Ginebra-Estocolmo. La película fue bastante famosa por su espectacular y sangrienta secuencia del descarrilamiento del tren.

Señal de alarma / Warning Sign (Hal Barwood, 1985). Un laboratorio civil para investigar microorganismos que puedan ser usados en la agricultura en realidad es una tapadera para producir armas biológicas. Consiguen crear una cepa de Lactobacillus luminiensis (sic) que porta genes del virus Borna y que además se transmite por el aire. Los infectados sufren primero 
de sudoración fluorescente y al cabo del tiempo se transforman en locos paranoides agresivos cubiertos de ampollas fluorescentes. Una curiosidad de esta película es que es la primera vez que se usó el símbolo de biopeligro en un póster cinematográfico.

El último patriota / The patriot (Dean Semler, 1998). Unos milicianos supremacistas consiguen robar un virus letal de un laboratorio de armas biológicas y planean realizar un chantaje a las autoridades. Con lo que no contaban es que se enfrentan a Steven Seagal, que además de ser experto karateka, también tiene un doctorado en inmunología y en remedios tradicionales indios. Así que no le cuesta mucho descubrir que un simple té a base de flores es el mejor remedio para detener la infección. La secuencia final de los helicópteros militares regando con flores todo el pueblo es una oda al movimiento flower power.

Misión: Imposible 2 / Mission: Impossible II (John Woo, 2000). En este caso una malvada compañía farmacéutica desarrolla un virus mutante de la gripe al que bautiza como Quimera. En paralelo desarrolla su cura a la que denomina Belerofonte. La idea de la compañía es liberar el virus, provocar una pandemia, y enriquecerse vendiendo la cura. La película está llena de gazapos como que el virus tiene capacidad de infectar los glóbulos rojos y que parece llevar un cronómetro incorporado, pues no se convierte en contagioso hasta que no es incubado durante veinte horas exactas en el cuerpo del paciente. $\mathrm{Ni}$ un minuto más, ni uno menos.

Invasión / The Invasion (Oliver Hirschbiegel y James McTeigue, 2007). En este flojo remake del clásico de la ciencia ficción La invasión de los ladrones cuerpos (Don Siegel, 1956), se cambia a las plantas alienígenas por un virus. El patógeno consigue infectar a un incompetente inspector del CDC y "duplicarle", ya que toma control de sus neuronas durante la fase de sueño REM. A partir de ahí la trama haría las delicias de cualquier conspiranoico, porque el CDC inicia una campaña de vacunación contra el virus extraterrestre, cuando en realidad lo que está haciendo es infectar a la población con el patógeno. Con lo que no contaban los alienígenas es que Nicole Kidman descubrirá que los que han padecido encefalitis por sarampión son inmunes a la infección.

\section{DISTOPÍAS VÍRICAS}

Otro subgénero a considerar es el de las películas que muestran cómo las sociedades son completamente transformadas, cuando no completamente aniquiladas, por la acción de un patógeno, generalmente de tipo vírico. En este tipo de películas hay dos clases principales: aquellas en las que el patógeno causa una gran mortalidad y aquellas en las que el patógeno transforma al infectado en un zombi agresivo.

Apocalipsis / The Stand (Mick Garris, 1994). Adaptación de la famosa novela de Stephen King en la que se describe cómo el escape de un virus mutante de la gripe, desarrollado como arma biológica y con una mortalidad del $99,99 \%$, se extiende por todo el planeta y acaba con la civilización. En el libro es realmente interesante el relato que describe el colapso social y sanitario causado por la enfermedad. Dicha parte no fue muy bien reflejada en la serie de televisión, aunque en breve, se va a estrenar una nueva adaptación de mayor duración que quizás sí la recoja.

28 días después / 28 days later (Danny Boyle, 2002) y su secuela 28 semanas después / 28 weeks later (Juan Carlos Fresnadillo, 2007). De nuevo tenemos a un virus mutante de la rabia desarrollado por los militares y que es liberado por el ataque de un grupo ecologista a las instalaciones. En la primera película el virus ha conseguido extenderse por casi toda la isla de Gran Bretaña. El guion en realidad es una adaptación de la historia de ciencia-ficción "El día de los trífides", pero con locos rabiosos en lugar de plantas. Pero ambas tienen bastantes secuencias 
interesantes desde el punto de vista microbiológico. En la primera por ejemplo tenemos un caso de infección a través de la conjuntiva del ojo, mientras que en la segunda tenemos el caso de un portador asintomático.

Infectados / Carriers (David Pastor, Àlex Pastor 2009). El estreno de esta película coincidió con el aviso de posible pandemia con la gripe H1N1. Es una "road movie" apocalíptica de cuatro supervivientes en un mundo que ha sido asolado por un virus altamente contagioso. En la película aparecen varias situaciones que podrían ser usadas para discutir temas de bioética como es el auxilio a los enfermos, de salud pública por medio del confinamiento, medidas de protección para evitar contagios, etc. Los protagonistas se enfrentarán a una serie de situaciones y sus decisiones se verán condicionadas por su miedo a quedar infectados, por su egoísmo y por su deseo de sobrevivir a toda costa.

The Walking Dead (Frank Darabont, Angela Kang, 2010). Podría decirse que esta serie de televisión es la apoteosis de los zombis como fenómeno cultural. En el año 2015 se estrenó la precuela Fear the Walking Dead (Robert Kirkman y Dave Erickson) en el que se indica que el paciente cero del virus Walker es una drogadicta, sin embargo, los aspectos científicos más interesantes se siguen encontrando en la serie original. Dejando de lado el hecho de que un zombi no cumple las leyes de la termodinámica, yo destacaría dos secuencias en particular. Una es el triple gazapo presente en el capítulo 5 - "Wildfire"durante la secuencia en la que el patólogo Edwin Jenner (Noah Emmerich) está procesando unas muestras que contienen el virus en un laboratorio BSL-4 del CDC de Atlanta. En la secuencia podemos ver que observa la multiplicación del virus con su triple hélice de ácido nucleico, a través de un microscopio óptico, sin oculares. Otra parte interesante está en el capítulo 6 - "TS-19". En ese capítulo no solo está la famosa secuencia del escáner funcional del cerebro de una persona que se transforma en zombi ${ }^{10}$. También está el descubrimiento de que todos los protagonistas están infectados con el virus Walker y que cuando alguien muere, el virus se activa y se produce la transformación en un zombi. Ese hecho argumental está basado en el dato científico de que un $8 \%$ del genoma humano tiene su origen en provirus que se insertaron en el pasado remoto.

La gripe / Gamgi (Sung-su Kim, 2013). Aunque no fue estrenada en España, esta película es fácil de encontrar en algunas plataformas desde que el cine surcoreano ganó el óscar por Parásitos. En este caso los surcoreanos han tomado los guiones de Estallido y Contagio, los han exagerado, han añadido un romance ñoño, unos cuantos litros de sangre y vísceras, lo han agitado bien y les ha salido un cóctel bastante gore. En lugar de mono capuchino, lo que tenemos es a un pobre inmigrante vietnamita que es el portador de una cepa mutante del virus de la gripe H5N1. Este inmigrante llega al distrito de Budang, cerca de Seúl y allí comienza un brote que parece imparable. Si en Contagio teníamos a gente tosiendo y delirando de fiebre por las calles, aquí tenemos a todo el centro de una ciudad llena de gente con eritema severo y vomitando sangre. Y si en Estallido veíamos la incineración de un granero lleno de cadáveres, aquí lo que vemos es todo un estadio manejado con palas excavadoras.

Guerra Mundial Z / WWZ (Marc Foster, 2013). Esta película bien podría haberse titulado "Brad Pitt y su familia contra los zombis". Teóricamente es la adaptación de un famoso libro escrito por Max Brooks, pero lo cierto es que lo único que tiene en común con dicha obra son los zombis. Si embargo es tan famosa, que lo cierto es que puede ser muy aprovechable en las clases de microbiología. Por ejemplo, la secuencia de la transformación de una persona en zombi en tan solo 10 segundos podría dar para discutir si la zombificación es producida por un virus o si podría ser explicada de mejor manera por un prión. Otro tema podría ser la plausibilidad de 


\section{EPIDEMIAS AL ESTILO HOLLYWOOD. UN PEQUEÑO CATÁLOGO \\ MANUEL SÁNCHEZ-ANGULO}

que los zombis "reconozcan" a los seres humanos afectados por una patología y no les ataquen.

Infección (Flavio Pedota, 2019). No es la primera vez que se usa el cine de zombis para hacer crítica social de la sociedad capitalista, pero lo curioso es que en este caso es para criticar al régimen chavista. Como en Fear the Walking Dead, el paciente cero es un drogadicto que está infectado con el virus de la rabia. La droga causa una mutación en el virus que acelera la aparición de los síntomas. Es de destacar que aquí los infectados no se transforman en un santiamén, sino que primero pasan por un estado febril y llegan a perder la consciencia antes de volverse violentos. Además, es bastante interesante que se indique que los afectados son llevados al hospital, con lo que la transmisión afecta al personal sanitario. Tampoco falta una secuencia en un centro de investigación donde se consigue observar que es un lyssavirus mutante, aunque de nuevo se comete el gazapo de usar un microscopio óptico y en la pantalla lo que se ve es una especie de tardígrado, no un virus.

\section{EL ZOMBI COMO PACIENTE}

Creo que George A. Romero nunca pudo imaginar que los zombis se iban a convertir en uno de los iconos culturales más potentes de la sociedad actual. El fenómeno ha evolucionado de tal forma que ya hay diversas películas y series en las que se muestra "el otro lado". El zombi ya no es un muerto viviente que hay que destruir, es un enfermo que puede ser tratado e incluso curado. El círculo se ha cerrado.

Retornados / The Returned (Manuel Carballo, 2013) y la serie de televisión In the flesh (Dominic Mitchell, 2013) tratan precisamente de una situación en la que se ha desarrollado una cura para la epidemia zombi. Sin embargo, la cura no es permanente y si dejan de medicarse, los afectados vuelven al estado de zombi rabioso. Esto da pie a difíciles situaciones de convivencia entre los enfermos y el resto de la población, ya que muchos de ellos han cometido crímenes de los cuales no son legalmente responsables, pero que no han sido olvidados por el resto de la comunidad.

Maggie (Henry Hobson, 2015). Sorprende ver a Arnold Schwarzenegger en el papel de padre amante de una hija que ha sido víctima del mordisco de un zombi y que poco a poco va transformándose sin remedio. En realidad es una película sobre las difíciles decisiones que puede llegar a tomar un familiar en el caso de una enfermedad terminal de uno de sus seres queridos.

\section{CONCLUSIÓN}

El catálogo presentado aquí no pretende ser exhaustivo aunque permite discernir algunas pautas. De las 62 películas listadas en la tabla 1 podemos ver que en 18 la enfermedad se origina por el uso de un arma biológica. En cuanto al tipo de enfermedad, si la película está ambientada en épocas pasadas la enfermedad epidémica que más aparece es la peste bubónica seguida de la viruela. En cambio, si la epidemia está ambientada en la actualidad, la preferencia entonces es un virus letal, o bien un virus zombificante. En algo menos de la mitad de las películas se consigue desarrollar un remedio contra el patógeno que suele ser o una vacuna o un suero hiperinmune. En las que no se desarrolla dicho remedio, o bien el patógeno es contenido con éxito, o el desenlace suele ser un escenario apocalíptico. Está claro que el cine es y será una fuente inagotable de escenarios en los que ver el efecto de los microorganismos patógenos sobre las comunidades humanas. Y probablemente la actual pandemia de COVID-19 inspirará unos cuantos guiones para las producciones futuras.

\section{REFERENCIAS}

1. Sánchez-Angulo M. De aniquiladores a salvadores. La microbiología en el cine. Making of: cuadernos de cine y educación. 2013; 100-101: 80-91. 


\section{EPIDEMIAS AL ESTILO HOLLYWOOD. UN PEQUEÑO CATÁLOGO \\ MANUEL SÁNCHEZ-ANGULO}

2. Pandemic Influenza Preparedness and Response: A WHO Guidance Document. Geneva: World Health Organization; 2009. 4, The WHO pandemic phases.

3. Carabias Martin F. La amenaza de las plagas: Pánico en las calles (1950). Rev Med Cine. 2006; 2(3): 89-95.

4. Sánchez M. Bioseguridad y armas biológicas: La amenaza de Andrómeda (1971). Rev Med Cine. 2011; 7 (1): 15-20.

5. Sánchez-Angulo M. Contagio. UMH Sapiens. 2020; 28: 10-2.

6. Camacho Aguilera JF. Epidemia: Un repaso a la fiebre hemorrágica por Ébola. Rev Med Cine. 2013; 9(2): 70-81.
7. Camacho Aguilera JF. Soy leyenda: comparación de la infección por el ficticio virus Krippin y el virus de la Rabia. Rev Med Cine. 2014; 10(1): 26-36.

8. Moreno-Chinchay N, Ramirez-Orellana J. Neurología: la cura del Alzheimer. De la ficción a la realidad. El origen del planeta de los simios (2011). Rev Med Cine. 2013; 9(3): 105-6.

9. García Sánchez JE, García Sánchez, E. La viruela y el cine histórico Rev Med Cine. 2020; 16(2): 123-130.

10. Hernández Yépez $P$, Contreras Pulache, H. Lo que dijeron las neurociencias en el apocalipsis zombi: "The Walking Dead" TS-19 (2010). Rev Med Cine. 2019; 15(2): 121-124.

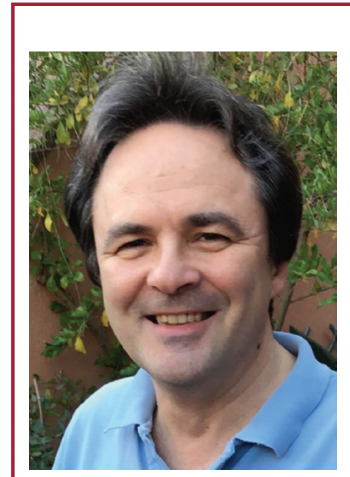

Manuel Sánchez Angulo. Profesor Titular del Departamento de Producción Vegetal y Microbiología de la Universidad Miguel Hernández, donde imparte docencia en el grado de Biotecnología y ha realizado diversas tareas en el campo de la educación, la innovación docente y la divulgación científica. Su línea de investigación es el desarrollo de nuevos antibacterianos contra el patógeno Streptococcus pneumoniae. Es miembro de la junta directiva de la Sociedad Española de Microbiología (SEM) en su calidad de director editorial de la revista SEM@foro. También es responsable del blog de divulgación científica "Curiosidades de la Microbiología", de la sección "El Biofilm" dedicado a comentar películas relacionadas con la Microbiología en el boletín NoticiaSEM, y del programa radiofónico de divulgación científica "Contraste de fases" que se emite por Radio UMH. 